\title{
Leachability of Self-Compacting Concrete (SCC) Incorporated With Fly Ash and Bottom Ash by Using Static Leaching Procedure (SLT)
}

\author{
Aeslina Abdul Kadir ${ }^{1, a}$, Mohd Ikhmal Haqeem Hassan², b, \\ Syed Khairul Hafizi Bin Syed Mohamad ${ }^{3, \mathrm{c}}$ \\ 1, 2, ${ }^{3}$ Faculty of Civil and Environmental Engineering, \\ Universiti Tun Hussein Onn Malaysia (UTHM), \\ 86400 Parit Raja, Batu Pahat Johor, Malaysia \\ Corresponding email: aaeslina@uthm.edu.my, ${ }^{\mathrm{b}}$ mohd.ikhmal.haqeem@gmail.com, \\ 'syedkhairul91@gmail.com
}

Keywords: self compaction concrete; fly ash; bottom ash; waste products; leachability; heavy metals.

\begin{abstract}
The growing demand for electricity resulted in the construction of many coal fired power plants. The increment of the consumption of coal by power plants lead up to production of coal ash. Coal ash contains a range of toxic elements that may have negative effects to human and environmental health. Fly ash (FA) and bottom ash (BA) are the solid residues and mostly arise from coal combustion that being disposed in large quantities every year. The focus of the study is to determine the leachability of Self Compacting Concrete (SCC) incorporated with FA and BA by using Static Leachate Test (SLT) method. In this study, FA and BA were collected from Kapar Energy Ventures Coal Power Plant in Selangor. The characteristics of Ordinary Portland cement (OPC), FA and BA were determined by using X-Ray Fluorescent (XRF) technique. The different percentages of FA (replace cement) and BA (replace sand) which is $0 \%, 10 \%, 20 \%$ and $30 \%$ were incorporated respectively into SCC. Ten reactors were set up for the leachability test for each solid specimen by using SLT method. The concentrations of leachate samples were analyzed for selected heavy metals content by using Atomic Absorption Spectroscopy (AAS) method. After 40 days conducting the test, the concentrations of selected heavy metals ( $\mathrm{As}, \mathrm{Mn}, \mathrm{Cu}, \mathrm{Cr}, \mathrm{Zn}, \mathrm{Ni}, \mathrm{Fe}$ and $\mathrm{Pb}$ ) in the synthetic acid rain leachates from the SCC specimens were significantly lower than the limit specified by the USEPA and EPAV. Therefore, incorporating of FA and BA up to $30 \%$ into SCC is potentially feasible.
\end{abstract}

\section{Introduction}

Coal has been one of the most important primary energy sources for countries all over the world. According to Association of Canadian Industries Recycling Coal Ash (CIRCA), 2010, worldwide coal reserves are estimated to be $8 \times 1012$ tones with annual consumption of $5 \times 109$ tones among which the majority is consumed by electric power utilities. Coal combustion products; predominantly consist of FA and BA are typically treated as waste materials and usually disposed into secure landfills and ash pond. The general production of coal ash mostly consists of FA and BA approximately in the ratio of $80: 20$ by weight [1].

Basically, there are about $10 \%$ total weights of the coal burned produces ash [2] with very high environmental risk. FA can be recognized as a fine grey powder consisting mostly of spherical in shape and their surfaces appeared to be smooth [3]. On the other hand, BA is coarse, with grain sizes spanning from fine sand to fine gravel ranging between $10 \mathrm{~mm}$ to $0.075 \mathrm{~mm}$ and typically grey to black in color $[4,5]$.

At present, the utilization of FA and BA from power stations includes in road construction, brick making and the production of cement and concrete. FA is the famous type of cement replacement material to replace the certain amount of cement content in the concrete and can be increased the workability properties of SCC mix. Reference [6] state the cementitious compound in FA may 
produce when siliceous material reacts with calcium hydroxide at the presence of water at ordinary temperature. Meanwhile, many investigations found that the BA has some cementaneous properties in which may increase the strength and long-term than concrete with natural sand [7].

Even though, the utilization of FA and BA have been practiced in worldwide with positive results, but weathering and erosion over time will ultimately cause the heavy metal contents have a tendency to leach out and a diversely would affect human and environmental health. Therefore, this research was conducted to determine the leachability of SCC incorporated with fly ash and bottom ash by using static leachate test (SLT) method.

\section{Experimental Programs}

Materials. FA and BA were collected from Kapar Energy Ventures (KEV) Coal Power Plant in Selangor. The XRF test was conducted to determine the chemical content of FA, BA and OPC. FA and BA were become part of the SCC mix composition by replacing cement and sand in the percentages of $0 \%, 10 \%, 20 \%$ and $30 \%$ respectively. Ten design mix proportions were made, which had total binder content of $530 \mathrm{~kg} / \mathrm{m}^{3}$ to $550 \mathrm{~kg} / \mathrm{m}^{3}$. The workability of the design mix proportions was determined by referring to specification and guidelines for SCC prepared by EFNARC [8].The size of specimens used throughout this research was $150 \mathrm{~mm}^{3}$ cubes. There were 10 specimens of SCC were prepared for conducting the static leachate test.

Testing of the specimens. Each mixed proportions were tested for their workability of SCC in order to classify it at SCC. These tests are the filling ability, passing ability and segregation resistance according to BS EN 12350-8, 12, 11 [9] respectively. Curing was then done in accordance to BS EN 12390-2 and compressive strength at 28 days were determined from compression test in BS EN 12390-3 [10].

The static leachate test was conducted to investigate the mechanism of leaching from solidified waste forms [18-19].The objective of the test is to study the long-term leaching behavior and to determine maximum concentrations of heavy metals leached out from both fly ash and bottom ash. Ten reactors were prepared to locate or submerged the SCC specimens (Fig.1) containing percentages of $0 \%, 10 \%, 20 \%, 30 \% \mathrm{FA}$ and BA respectively into synthetic acid rain leachant. A dilute sulphuric acid/nitric acid (60/40 weight percent mixture) was used to prepare the solution until the $\mathrm{pH}$ was attained $4.2 \pm 0.05$. The USEPA Regulatory Method 1312 - Synthetic Precipitation Leaching Procedure (SPLP) [11] with some modification was used as a reference. The leaching of the solidified waste specimen without renewal of leaching solution was collected over durations of $4,8,12,16,20,24,28,32,36$ and 40 days. Then, all the samples were analyzed for the concentrations of heavy metals by using Atomic Absorption Spectroscopy (AAS) method.

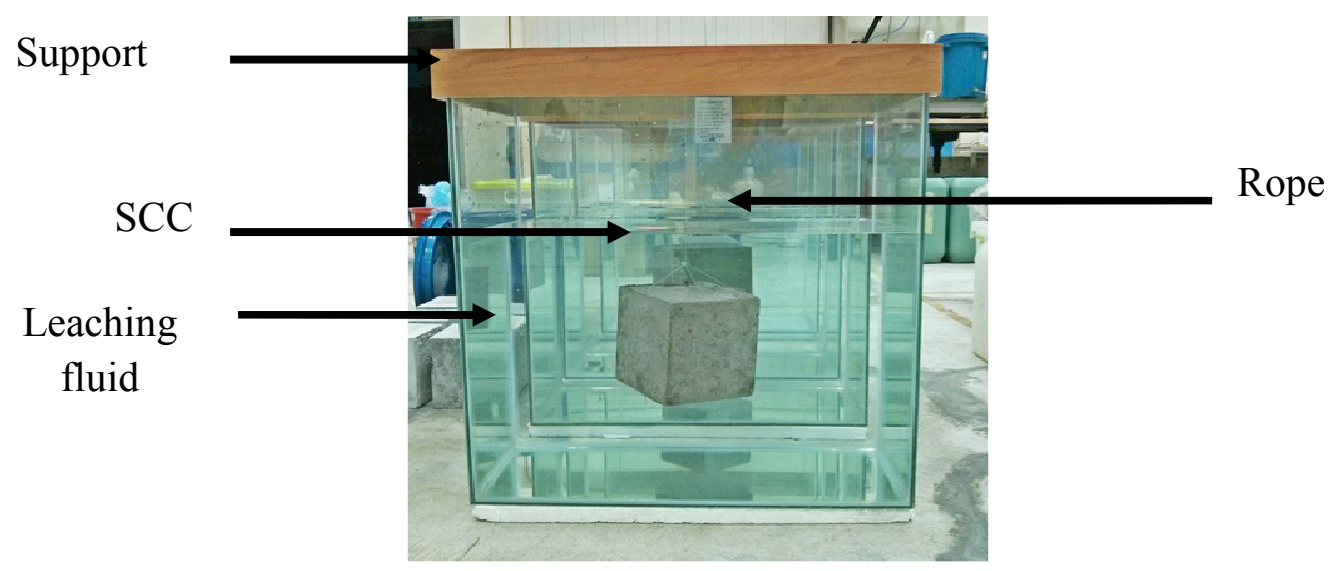

Figure 1: Static Leachate Test 


\section{Result and Discussions}

Characteristics of the Materials. The chemical compositions of ordinary Portland cement (OPC), FA and BA were determined by using X-Ray Fluorescent (XRF) test. A total of 26 chemical compounds or elements were detected in FA, BA and OPC. However there were 8 elements involved in the analysis of the leachability of SCC incorporated with FA and BA and detectable by Atomic Absorption Spectrometry (AAS). These elements are As, $\mathrm{Cr}, \mathrm{Pb}, \mathrm{Zn}, \mathrm{Cu}, \mathrm{Ni}, \mathrm{Mn}$ and $\mathrm{Fe}$.

Leachability of heavy metals. Ten SCC specimens with different design mix proportion which is control specimen, FA10BA0, FA20BA0, FA30BA0, FA0BA10, FA0BA20, FA0BA30, FA10BA10, FA20BA20 and FA30BA30 (Fig. 2-11) were analyzed for the concentrations of selected heavy metal elements (As, $\mathrm{Mn}, \mathrm{Cu}, \mathrm{Cr}, \mathrm{Zn}, \mathrm{Ni}, \mathrm{Fe}$ and $\mathrm{Pb}$ ) along the period of 4, 8, 12, 16, 20, 24, 28, 32, 36 and 40 days by using AAS method.

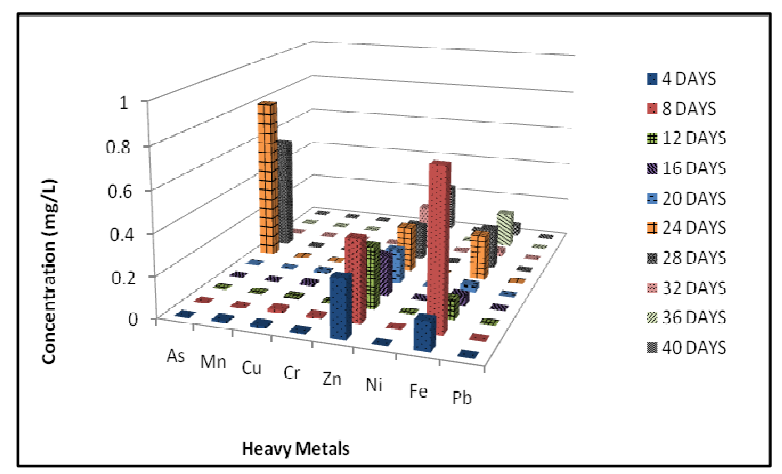

Figure 2 : Comparison of heavy metal concentrations in SCC (control) for different leaching periods using SLT

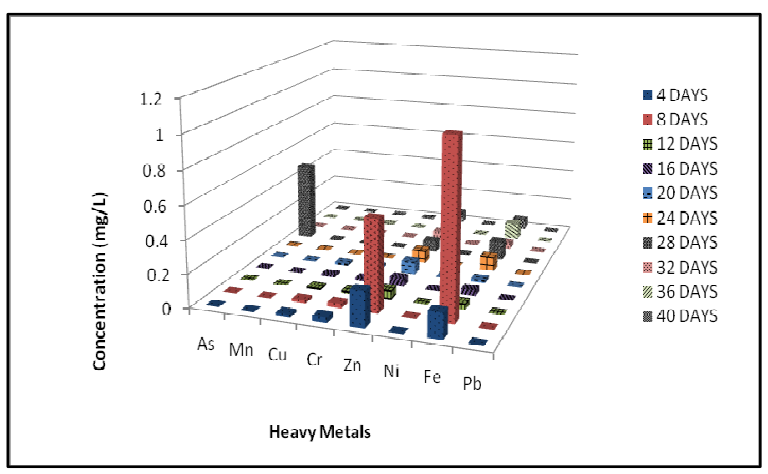

Figure 4: Comparison of heavy metal concentrations in SCC Figure 5: Comparison of heavy metal concentrations in (FA20BA0) for different leaching periods using SLT

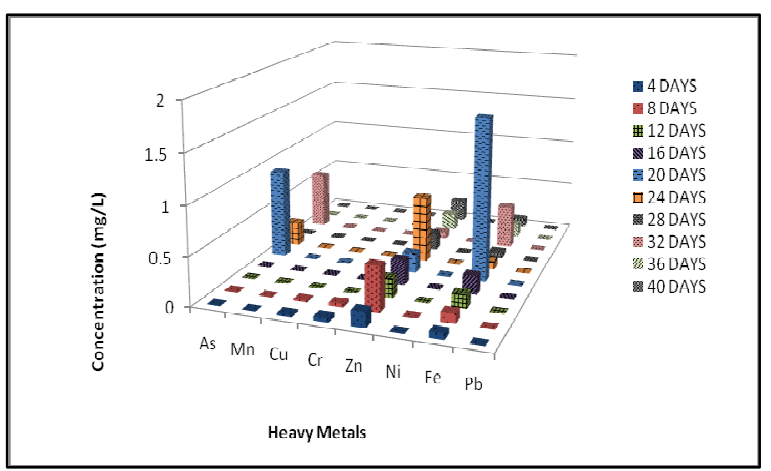

Figure 6: Comparison of heavy metal concentrations in SCC (FA0BA10) for different leaching periods using SLT

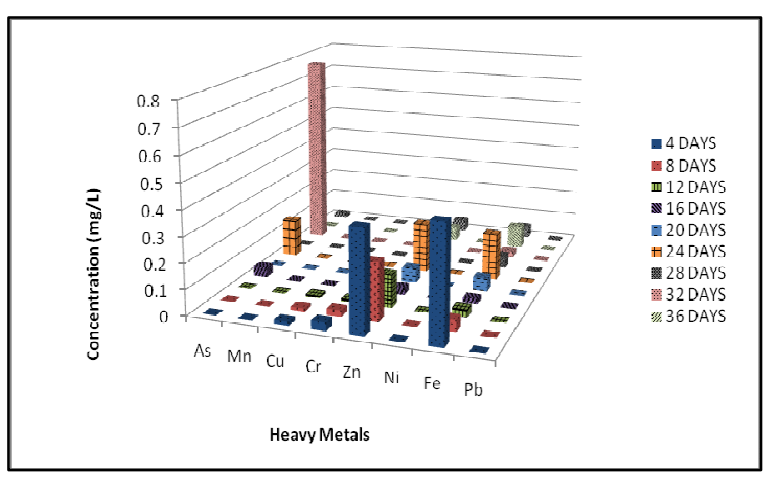

Figure 3: Comparison of heavy metal concentrations in SCC (FA10BA0) for different leaching periods using SLT

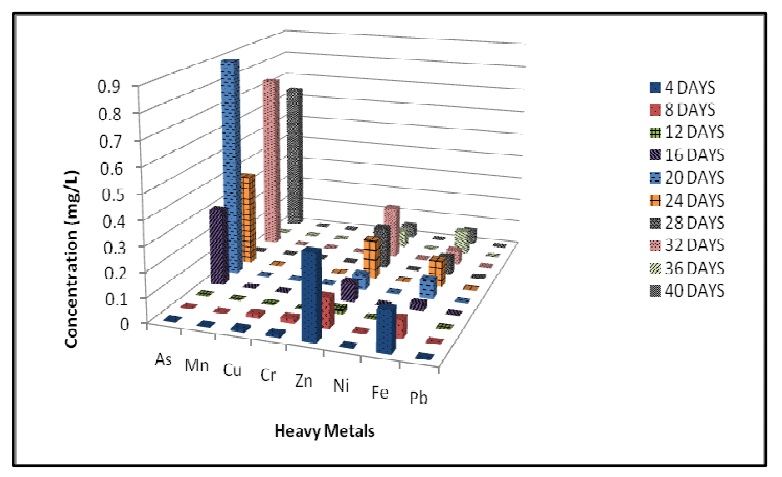
SCC (FA30BA0) for different leaching periods using SLT

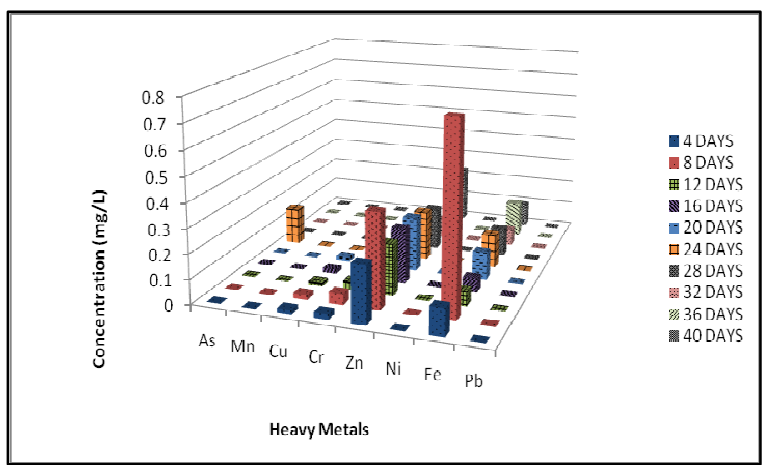

Figure 7: Comparison of heavy metal concentrations in SCC (FA0BA20) for different leaching periods using SLT 

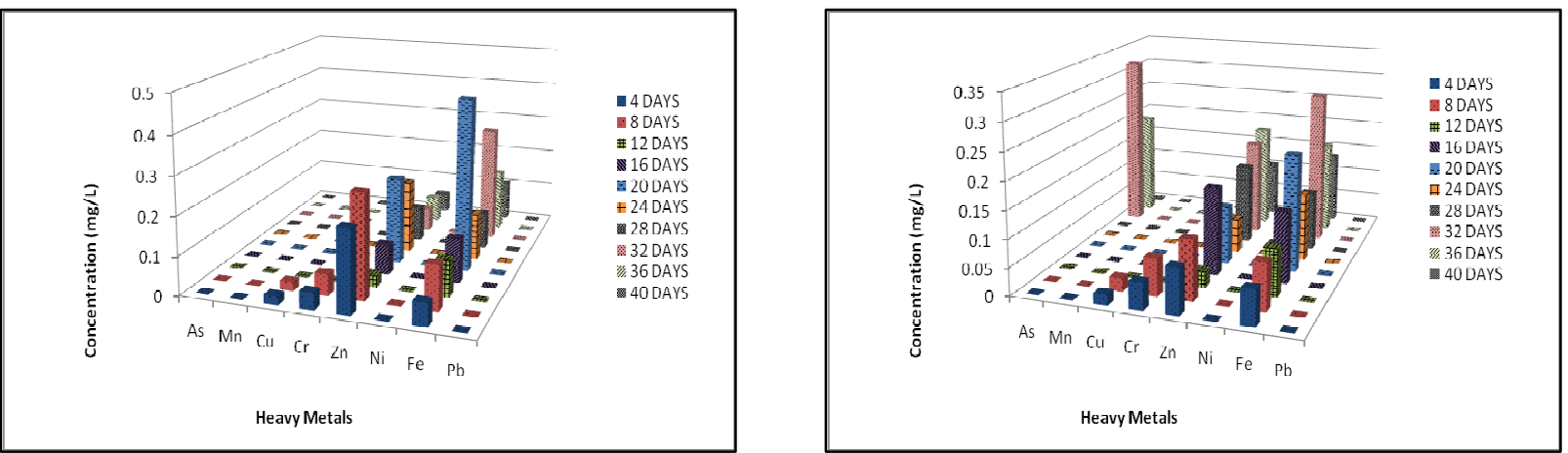

Figure 8: Comparison of heavy metal concentrations in SCC Figure 9: Comparison of heavy metal concentrations in (FA0BA30) for different leaching periods using SLT SCC (FA10BA10) for different leaching periods using SLT
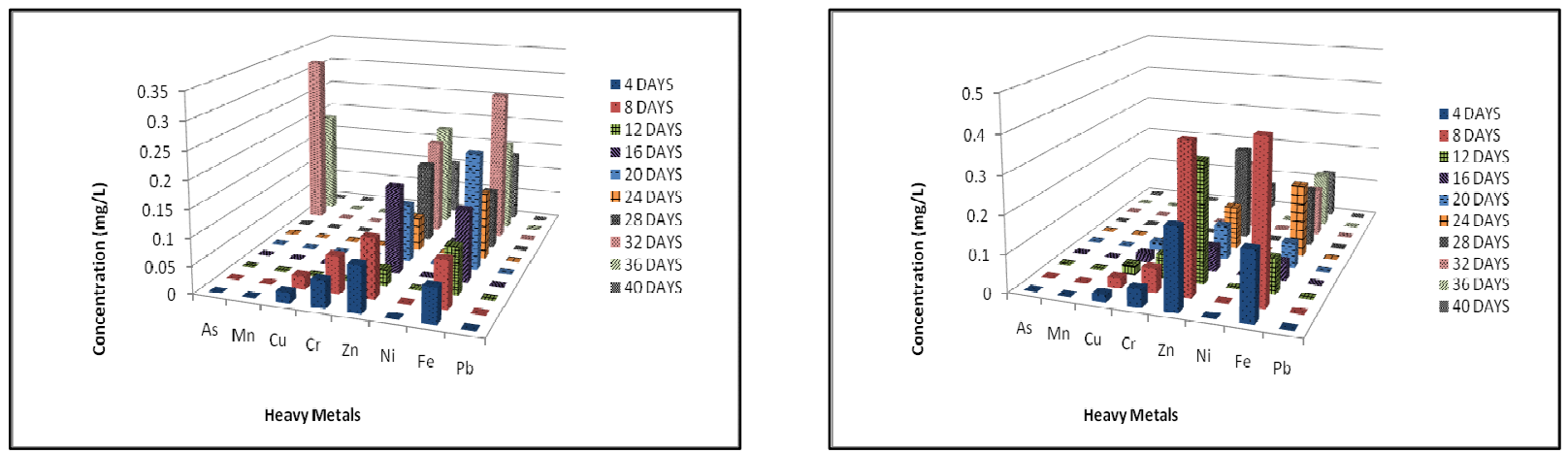

Figure 10: Comparison of heavy metal concentrations in SCC Figure 11: Comparison of heavy metal concentrations (FA20BA20) for different leaching periods using SLT in SCC (FA30BA30) for different leaching periods using SLT

The concentrations of selected heavy metals ( $\mathrm{As}, \mathrm{Mn}, \mathrm{Cu}, \mathrm{Cr}, \mathrm{Zn}, \mathrm{Ni}, \mathrm{Fe}$ and $\mathrm{Pb}$ ) in the synthetic acid rain leachant collected from the SCC specimens were significantly lower than the limit specified by the USEPA (1996) and EPAV (2005) [12-13]. The materials of FA and BA maybe bound up in the SCC due to the lack of heavy metals concentration leach from the specimens. The concentrations of heavy metals in the leachate was lower than the detection limit is due to the solidification/stabilization process that takes place when apply cement binders [14]. Besides that, the immobilization of heavy metals is believed to be caused by chemical changes like pozzolonic reactions incorporate into a solid matrix during the process of solidification take place $[15,16]$.

\section{Conclusions}

The concentration of heavy metals elements such as $\mathrm{V}, \mathrm{Cr}, \mathrm{Ni}, \mathrm{Cu}, \mathrm{Zn}, \mathrm{As}, \mathrm{Ba}$ and $\mathrm{Pb}$ showed that FA contained the highest concentration value compared to OPC and BA. The casting process of SCC were involved ten different design mix proportions involved $0 \%$ of fly ash and bottom ash (control sample), 10\%, 20\% and 30\% of fly ash, 10\%, 20\% and 30\% of bottom ash and combination of $10 \%, 20 \%$ and $30 \%$ of fly ash and bottom ash. After 40 days conducting the static leachate test on ten specimens of SCC, the results obtained from AAS test shows that the concentrations of all heavy metal elements detected were significantly lower than the limit specified by the USEPA and EPAV.As a conclusion, the utilization of fly ash and bottom ash up to $30 \%$ to be incorporated into SCC are potentially feasible and these materials are safe to be implemented as a part of the building materials. 


\section{References}

[1] ACAA, Coal Combustion Product (CCP) Production and Use Survey.Ash at work (Winter/Spring):25, (2003).

[2] H.W. Huang. The Use of Bottom Ash in Highway Embankments, Subgrade and Subbases. Joint Highway Research Project, Final Report, FHWA/IN/JHRP- 90/4 Purdue University, W.Lafayette, Indiana, (1990).

[3] B.Kim, M. Prezzi, \& R. Salgado, "Geotechnical properties of fly and bottom ash mixtures for use in highway embankments.” J. Geotech. Geoenviron. Eng., 131(7), 914-924, (2005).

[4] M. Muhardi, A. Kasim, K.A., Makhtar, A.M., Lee, F.W. \& Yap, S.L. "Engineering Characteristic of Tanjung Bin Col Ash”. Vol. 15 [2010], Bunk. K. (2010).

[5] USEPA, (United State Environmental Protection Agency). Wastes - Resource Conservation Reduce, Reuse, Recycle - Industrial Materials Recycling. Available online http://www.epa.gov/epawaste/conserve/rrr/imr/ccps/flyash.htm (accessed on 12 ${ }^{\text {th }}$ April 2010).

[6] M.H. Syahrul, F. Muftah, \& Z. Muda. "The properties of special concrete using washed bottom ash (WBA) as partial replacement". International Journal of Sustainable Construction Engineering \& Technology. Vol. 1, No. 2 pp. 65-76. (2010).

[7] M.Sonebi. Medium strength self-compacting concrete containing fly ash: Modelling using factorial experimental plans. Cement Concrete Re; 34:1199-208. (2004).

[8] EFNARC, (European Federation of National Trade Associations representing producers and applicators of specialist building products). Specification and guidelines for self-compacting concrete. Hampshire, UK; February 2002.

[9] BS EN 12350: 2010, "Testing fresh concrete - part 8, 11 and 12: Self-Compacting Concrete " 2010 .

[10] BS EN 12390-3: 2000, “Testing hardened concrete - part 2: making and curing specimens for strength tests," 2000.

[11] USEPA, Synthetic Precipitation Leaching Procedure (SPLP), Method 1312, September 1994.

[12] USEPA, Hazardous Waste Characteristics Scoping Study, US Environmental Protection Agency, Office of Solid Waste, 1996.

[13] EPAV, Guidelines for Hazard Classification of Solid Prescribed Industrial Waste, Publication 996, June, 2005.

[14] J.M. Chimenos, O. Gines, A.Vizcarro, J.Formosa, \& J.R Rosell. Combined use of MSWI bottom ash and fly ash as aggregate in concrete formulation: Environmental and mechanical considerations. (2009).

[15] T. Sabbas, A. Polettini, R. Pomi, T. Astrup, O. Hjelmar, P. Mostbauer, G. Cappai, G. Magelf, S. Salhofer, C. Speiser, S. Heuss-Assbicher, P. Klein, R. Lechner. Management of municipal solid waste inceniration residues. Waste Manage.23, 61-88. (2003).

[16] J.Todorovic, H. Ecke, A. Lagerkvist. Solidification with water as a treatment method for air pollution control residues. Waste Manage, 23, 621-629.(2003). 